

\section{REVISTA \\ TEORÍA Y PRÁCTICA \\ DE LA \\ ARQUEOLOGÍA HISTÓRICA LATINOAMERICANA}

ISSN: 2250-866X (impreso) | ISSN: 2591-2801 (en línea)

AÑO VIII, VOLUMEN 9, PRIMAVERA DE 2019

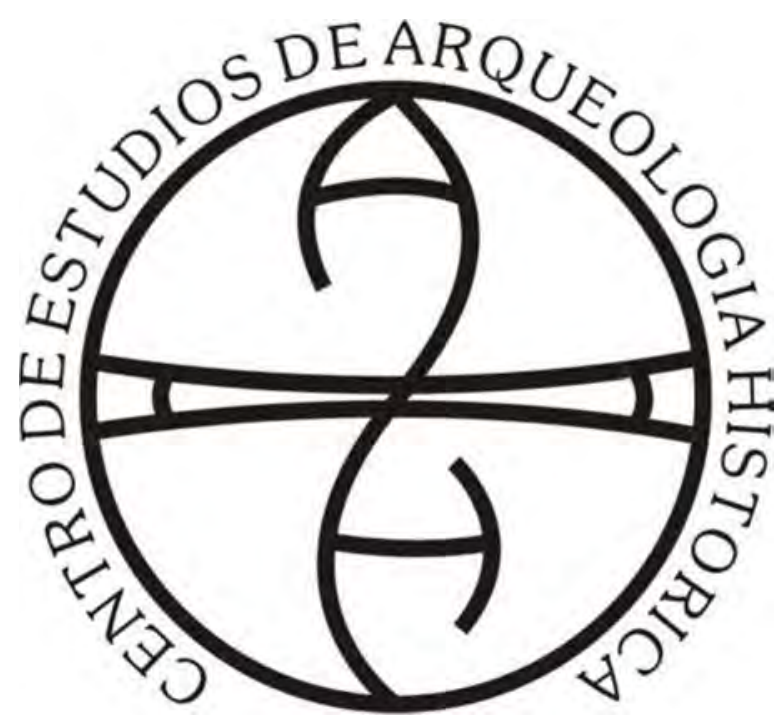

CENTRO de Estudios de ARqueOlOGía HistóricA

FACULTAD DE HUMANIDADES Y ARTES | UNIVERSIDAD NACIONAL DE ROSARIO 
(Universidad Nacional de Rosario, Universidad Nacional de Río Cuarto,

Universidad Nacional de San Juan, Universidad de la República, Universidad Nacional de Trujillo)

\author{
AUTORIDADES DE LA UNIVERSIDAD NACIONAL DE ROSARIO \\ RECTOR: Lic. Franco Bartolacci \\ VICE-RECTOR: Od. Darío Macía \\ SECRETARIO GENERAL: Prof. José Goity \\ SECRETARIA ACADÉMICO Y DE APRENDIZAJE: Dr. Marcelo Vedrovnik \\ SECRETARÍA DE CIENCIA TECNOLOGÍA E INNOVACIÓN \\ PARA EL DESARROLLO: Ing. Guillermo Montero.
}

\author{
AUTORIDADES DE LA FACULTAD DE HUMANIDADES Y ARTES \\ DECANO: Prof. Alejandro Vila \\ VICEDECANA: Prof. Marta Varela \\ SECRETARIA ACADÉMICA: Dra. Marcela Coria
}

\author{
AUTORIDADES DEL CENTRO DE ARQUEOLOGÍA HISTÓRICA \\ DIRECTORA: Dra. Ana Rocchietti \\ SECRETARIA: Prof. Nélida de Grandis \\ PROSECRETARIA: Lic. Marianela Bizcaldi
}

DIRECTORAS - EDITORAS:

Dra. Ana Rocchietti y Prof. Nélida De Grandis

SECRETARIA DE EDICIÓN: Dra. Irene Dosztal

Este número es co-edición de las ponencias

del VIII Congreso Nacional de Arqueología Histórica (2018) entre:

Centro de Estudios en Arqueología Histórica: Directora Ana Rocchietti

Centro de Estudios en Arqueología Regional: Director Fernando Oliva

Centro de Estudios en Arqueología Subacuática: Directora Mónica Valentini

Departamento de Arqueología, Escuela de Antropología: Director Fernando Oliva
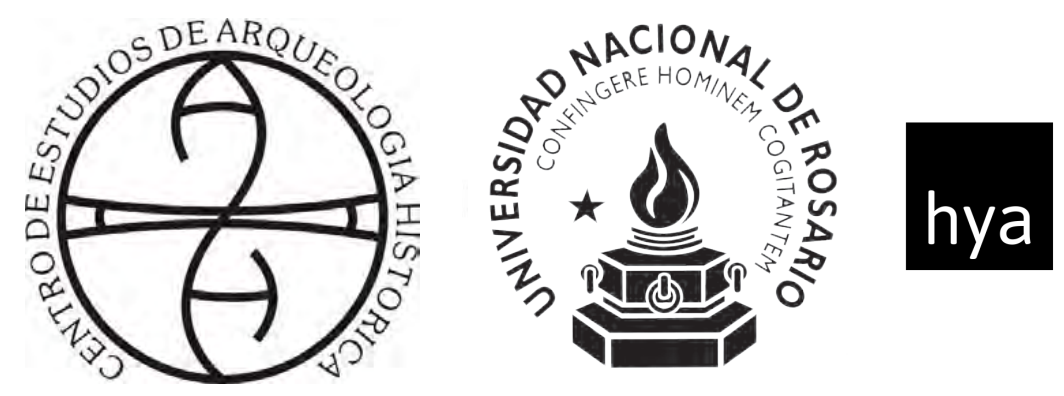

Facultad de Humanidades

y Artes_UNR
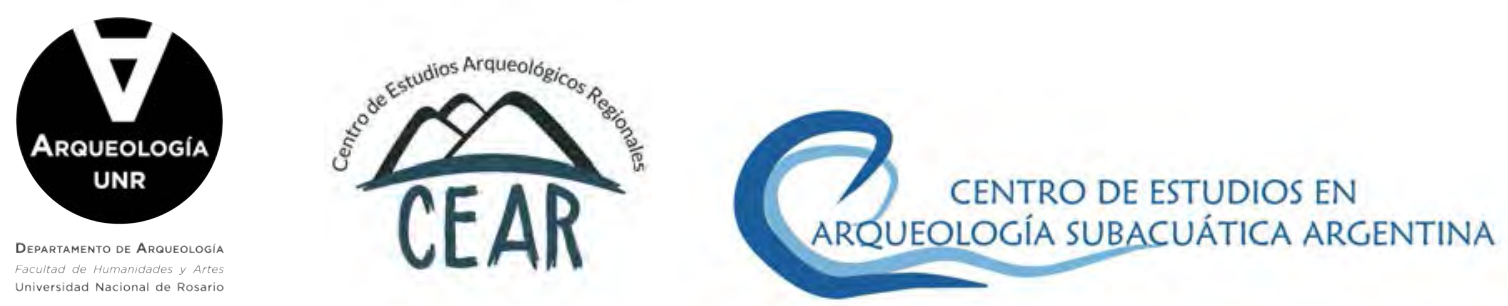
Comité Permanente de los Congresos Nacionales de Arqueología Histórica

Dr. Daniel Schávelzon (Universidad Nacional de

Buenos Aires)

Prof. María Teresa Carrara (Universidad Nacional de Rosario)

Prof. Carlos Baldassarre (Museo Municipal de Río

Grande, Tierra del Fuego) in memoriam

Dr. Mariano Ramos (Universidad Nacional de Luján, CONICET)

Dr. Horacio Chiavazza (Universidad Nacional de Cuyo)

Dra. Ana María Rocchietti (Universidad Nacional de

Rosario, Universidad Nacional de Río Cuarto)

Lic. Facundo Gómez Romero (Universidad Autónoma

de Barcelona)

\section{Comité Científico}

Dra. Tânia Andrade Lima (Universidade Federal do Rio de Janeiro)

Prof. Réginald Auger (CELAT/Département des

Sciences Historiques, Université Laval, Canadá)

Dr. Roberto Bárcena (Universidad Nacional de Cuyo, CONICET)

Dra. Marta Bonaudo (Universidad Nacional de Rosario, CONICET)

Dr. Leonel Cabrera (Universidad de la República, Uruguay)

Dr. Luis María Calvo (Universidad Católica de Santa

$\mathrm{Fe})$

Prof. Juan Castañeda Murga (Universidad Nacional de

Trujillo, Perú)

Dr. Carlos Ceruti (Museo de Ciencias Naturales y

Antropología "Prof. Antonio Serrano”. Paraná)

Dr. Horacio Chiavazza (Universidad Nacional de Cuyo)

Dra. Silvia Cornero (Universidad Nacional de Rosario)

Prof. Pedro Paulo Funari (Universidade Estadual de

Campinas, Brasil)

Lic. Jorge A. Gamboa Velásquez (Universidad Nacional

Santiago Antuñez de Mayolo, Perú)

Dr. Eduardo Alejandro García (Universidad Nacional de

San Juan, CONICET)

Prof. Nélida De Grandis (Universidad Nacional de

Rosario)

Dr. Juan Bautista Leoni (Universidad Nacional de

Rosario, CONICET)

Dra. Amancay Martínez (Universidad Nacional de San

Luis)

Dra. Catalina Teresa Michieli (Universidad Nacional de

San Juan, CONICET)

Lic. Fernando Oliva (Universidad Nacional de Rosario)
Ing. Adrián Pifferetti (Universidad Tecnológica Nacional Regional Rosario)

Dr. Mariano Ramos (Universidad Nacional de Luján, CONICET)

Dra. Ana María Rocchietti (Universidad Nacional de Rosario)

Dr. Daniel Schávelzon, (Universidad Nacional de Buenos Aires, CONICET)

Dra. Carlota Sempé (Universidad Nacional de La Plata)

Dr. Mario Silveira (Universidad Nacional de Buenos

Aires)

Dra. Silvia Simonassi (Universidad Nacional de Rosario)

Dra. Alicia Tapia (Universidad Nacional de Buenos Aires, Universidad Nacional de Luján)

Lic. Mónica P. Valentini (Universidad Nacional de Rosario)

Agrim. Benito Vicioso (Universidad Nacional de Rosario)

\section{Evaluaron este volumen}

Roberto Bárcena, María Teresa Boschin, Leonel Cabrera, Ulises Camino, María Rosa Carbonari, Carlos Ceruti, Horacio Chiavazza, Nicolás Ciarlo, Silvia Cornero, Eduardo Crivelli, Javier García Cano, Martín Gentinetta, María Laura Gili, Carlos Landa, Matilde Lanza, Melina Malandrino, Sebastián Pastor, Victoria Pedrotta, Josefina Piana, Mercedes Podestá, Mariano Ramos, Daniel Schavelzon, Diana Tamburini, Mónica Therrien, Mónica Valentini y María Teresa Boschin

\section{Diseño y diagramación}

Eugenia Reboiro

(eugenia.reboiro@gmail.com)

\section{Curadoría}

Ana Rocchietti e Irene Dosztal

Foto de tapa: Material arqueológico, del texto de Tapia et al.

\section{Propietario responsable:}

Facultad de Humanidades y Artes, Universidad Nacional de Rosario Centro de Estudios de Arqueología Histórica

Entre Ríos 758. Rosario, provincia de Santa

Fe (2000). Argentina.

Telf.: +54 (0341) 4802670

E-mail: ceahunr@gmail.com

Decreto Ley 6422/57 de Publicaciones

Periódicas 


\section{Índice}

Editorial

El origen del patrimonio histórico y su conservación integral en la contemporaneidad.

Yanina Aguilar

Prospección de basurales históricos de la ciudad de Rosario.

Soccorso Volpe y Gustavo Fernetti

Desconstrucción de un paisaje urbano. El Montevideo del extramuros colonial, aportes de la arqueología a su identidad actual. Ana Gamas

La Calota de Ameghino: reconsiderando un viejo tema desde la arqueología histórica.

Daniel Schávelzon

Análisis zooarqueológico de los restos hallados en una estructura sanitaria vinculada a momentos tempranos del actual barrio de Belgrano .71 Mario Silveira, Horacio Padula, Ricardo Orsini y Eva Bernat

La medida del tiempo: el reloj solar jesuita de La Cruz, provincia de Corrientes.

Fernando Oliva y María Cecilia Panizza

Sitio La Quinta: arqueología rural de campos serranos.

Flavio Ribero

Si no hay tabaco que no se note. Prácticas fumatorias en el fortin La Perra (1883-1885), La Pampa.

Alicia Tapia, Virginia Pineau y Melisa Ayelén Auge

El uso del tabaco y las pipas de caolin (clay pipes) en la frontera sur y oeste de la provincia de Buenos Aires en el siglo XIX.. .127

María del Carmen Langiano y Julio Fabián Merlo 
Patrimonio natural, urbano y arquitectónico de la costa en Mar del Plata. Federico Negroni

Huellas urbanas.

Ezequiel Serrot

Paisaje y patrimonio. La industria taninera en el siglo XX.

Provincia de Santa Fe.

Cristina Pasquali, Paola Milicic y Lara Ferré

Los desafíos de las arqueologías históricas latinoamericanas.

Andrés Zarankin

Sellos entre escombrales. Las lozas en el registro urbano

del Área Fundacional de Mendoza (siglo XIX y principios del siglo XX)

Lorena Puebla y Horacio Chiavazza

Evolución edilicia de la Plaza de Mayo de la Ciudad

de Buenos Aires (1580-1853).

Nicolás Ferrino

Gestión patrimonial en el rescate arqueológico y futuro Museo de Sitio

en Moreno 550, Ciudad Autónoma de Buenos Aires, Argentina.

María Eva Bernat, Ricardo Orsini, Horacio Padula y Mario Silvera 


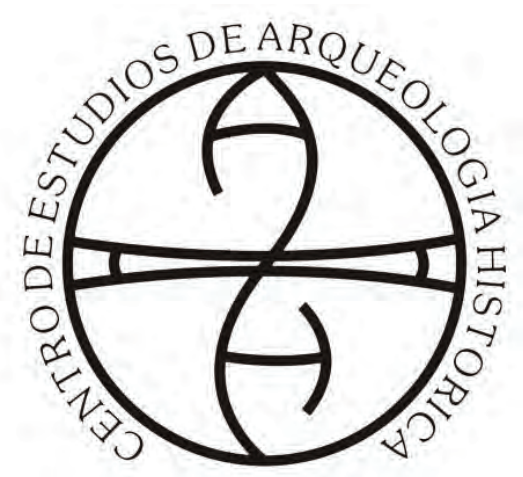

Centro de Estudios de Arqueología Histórica

Universidad Nacional de Rosario
Teoría y Práctica de la Arqueología Histórica

Latinoamericana | Año VIII. Vol. 9 | 2019

Revista del Centro de Estudios de Arqueología

Histórica, Facultad de Humanidades y Artes,

Universidad Nacional de Rosario

https://teoriaypracticaah.unr.edu.ar/index.php/index

ceahunr@gmail.com

ISSN en línea: 2591-2801

ISSN versión impresa: 2250-866X

\title{
ANÁlisis ZOOARQUEOLÓGICO DE LOS RESTOS HALLADOS EN UNA ESTRUCTURA SANITARIA VINCULADA A MOMENTOS TEMPRANOS DEL ACTUAL BARRIO DE BELGRANO
}

\author{
Mario Silveira, Horacio Padula, Ricardo Orsini y Eva Bernat*
}

\begin{abstract}
Resumen
La excavación de una estructura hallada en el Sitio Barrancas de Belgrano permitió establecer dos niveles de descarte muy definidos, donde se recuperaron materiales de origen cultural correspondientes a las últimas décadas del siglo XIX y principios del XX, y entre otro, con descartes más tempranos cuya cronología se sitúa entre fines del siglo XVIII y principios del XIX, y podría tener vinculación directa con la presencia de los franciscanos y su industria y los demás grupos humanos que se asentaron la zona en aquellos años

Fue en estos últimos estratos, en los cuales se recuperó el material más significativo, cuyos ejemplares demostraron presentar menores perturbaciones antrópicas y naturales, y revelaron un conjunto amplio, diverso y bien conservado de materiales culturales.

Entre los materiales más destacables pueden mencionarse: piezas de vajilla de loza inglesa, mayólica española y francesa, porcelana oriental, ollas y demás recipientes de terracota de producción europea y regional, botones de hueso, vasos de vidrio soplado con decoraciones grabadas, un basín de mayólica, botellas de bebidas alcohólicas, frascos, cuentas de vidrio, una botija española de uso mercantil, dos reales del siglo XIX, un florero de posible uso litúrgico y una importante cantidad de coquinas que pertenecen a la ingresión belgranense con su molusco fósil característico, la erodona (Erodona mactroides). De este conjunto nos ocupa el análisis del material óseo producto de la dieta de los moradores del sitio, donde se halló una importante cantidad de elementos de los cuales fue posible determinar taxonómicamente la mayor parte de sus restos por tratarse de un descarte primario. Tres de estos taxones son considerados domésticas (gallinas, ovinos y vacunos) y el resto producto de caza y pesca que presumimos fueron descartadas luego de su consumo. De las restantes especies, cuyos restos no consideramos de consumo, se han encontrado elementos óseos de animales domésticos como el caballo, gatos y perros.
\end{abstract}

*Centro de Interpretación de Arqueología y Paleontología de la Dirección General de Patrimonio, Museos y Casco Histórico (G.C.B.A.) 
Siendo las demás especies halladas, propias de un área salvaje y con cuerpos de agua cercanos característico de aquella época.

Palabras clave: Calera de los Franciscanos , Barrancas de Belgrano, Ingresión Belgranense- realesconsumo

\begin{abstract}
The excavation of a structure found in the Barrancas de Belgrano Site allowed to establish two levels of well-defined discards, where materials of cultural origin were recovered corresponding to the last decades of the XIX century and the beginning of the XX, and among other, with earlier discards whose chronology is between the late eighteenth and early nineteenth centuries, and could have direct link with the presence of the Franciscans and their industry and the other human groups that settled the area in those years

It was in these last strata, in which the most significant material was recovered, whose specimens showed less anthropic and natural disturbances, and revealed a broad, diverse and well-conserved collection of cultural materials.

Among the most noteworthy materials we can mention: pieces of English crockery, Spanish and French majolica, oriental porcelain, pots and other terracotta containers of European and regional production, bone buttons, blown glass with engraved decorations, a basin of majolica, bottles of alcoholic beverages, flasks, glass beads, a Spanish botija for mercantile use, two reals of the 19th century, a vase of possible liturgical use and an important quantity of coquinas that belong to the Belgranense Transgression with its characteristic fossil mollusc, called Erodona mactroides.

From this set we are concerned with the analysis of the bone material product of the diet of the inhabitants of the site, where an important amount of elements was found, from which it was possible to determine taxonomically most of its remains as it is a primary discarding. Three of these taxa are considered domestic (chickens, sheep and cattle) and the rest of the hunting and fishing products that we presume were discarded after consumption. Of the remaining species, whose remains we do not consider of consumption, bone elements of domestic animals such as horses, cats and dogs have been found. Being the other species found, typical of a wild area and water bodies nearby characteristic of that time.
\end{abstract}

Keywords: Franciscans Lime Works -Belgrano Hills- Belgranense Transgression - Real coins- feed

\title{
Introducción
}

La puesta en valor durante los años 2017 y 2018 del espacio público conocido como Barrancas de Belgrano, fue la ocasión propicia escogida por la Dirección General de Patrimonio, Museos y Casco Histórico, para emprender una intervención de tipo arqueológico en diversos sectores del paseo. Una de ellos, se concentró en el área en la cual se levantó a partir de 1726, la Capilla de los Franciscanos.

El asentamiento de esta orden religiosa en lo que se conocía como "La Calera” tuvo que ver con la presencia allí de "bancos de conglomerados de detritos” y la requerida práctica extractiva de dicho recursos destinados a la fabricación de cal para su uso durante la construcción de la Iglesia de San Francisco (Mille, 1961) en la actual esquina de las calles Defensa y Alsina.

El establecimiento de grupos humanos en "la Calera” constituye el primer asiento en lo que actualmente se conoce como barrio de Belgrano, considerando además que la extracción de recursos mencionada, se reprodujo en las barrancas durante más de un siglo. 
En consecuencia, uno de los principales ejes de los trabajos arqueológicos emprendidos, se llevó a cabo en un pozo de tamaño oval ubicado en las proximidades de la capilla, más precisamente, en los interiores de la casa adjunta y utilizada como “casa parroquial” ubicado en cercanías de la actual esquina de las calles La Pampa y Arribeños. Esta estructura pudo ser reconocida durante las tareas iniciales de prospección superficial emprendida en la barranca artificial ubicada sobre la calle La Pampa, en donde pudieron apreciarse tres hiladas de ladrillos de origen "preindustrial”

Esta estructura, corresponde a un pozo de balde o aljibe con pozo, los cuales eran excavados hasta la napa freática, en donde se acumula agua, la cual era extraída por medio de un balde y una roldana. (Schávelzon 2018)

\section{El proceso de recuperación de información}

A partir de la identificación de la estructura de ladrillos, se procedió a grillar la zona del talud comprendida entre los 23 y los 26 metros desde el límite oeste de la escalera de rocalla sita en la esquina con la calle Arribeños.

Se estableció un nivel “0”, localizado a 65 cm de altura desde la base de una farola próxima al área a intervenir, y se determinó el uso preliminar de niveles artificiales de $10 \mathrm{~cm}$.

El área grillada fue delimitada con cinta de peligro y vallas, y señalizada con un cartel informativo. Al finalizar cada jornada de excavación, la zona excavada se cubría con una lona, a fin de garantizar la seguridad de los transeúntes y de los restos patrimoniales.

Si bien se grillaron 15 cuadrículas de 1 x 1 metro, las tareas de excavación se concentraron en las 23-B, 24-B, 25-B, 23-C, 24-C y 25-C, las cuales comprenden la totalidad del perímetro de la estructura de ladrillos, identificada a partir del nivel 3. Adicionalmente, se excavaron en forma parcial las cuadrículas 24-A y 23-A, que se veían afectadas por cableados y otras obras recientes vinculadas con la parquización (Imagen $\mathrm{N}^{\circ} 1$ ).

A partir del nivel 9, se comienza a excavar el depósito contenido en el interior de la estructura como una única unidad estratigráfica (Unidad Estratigráfica 1), trabajando con niveles artificiales de $20 \mathrm{~cm}$. En total se excavaron 15 niveles, llegando a 3.05 metros de profundidad, momento en el cual ya no aparecen materiales culturales y se llega al sedimento estéril. Para recuperar materiales pequeños, el sedimento extraído se revisó minuciosamente en forma manual, ya que la humedad del mismo impedía su zarandeo con tamiz.

La estructura hallada, está formada en su mayor parte por ladrillos fracturados, unidos con mortero de barro, y tiene un perímetro ovalado orientado en sentido este-oeste. En el límite norte, a la hilada más superficial de ladrillos correspondiente a la estructura se superponen otras tres, esta vez de ladrillos enteros, colocados de forma ordenada y alternando su orientación. Estas tres hiladas de ladrillo resultan compatibles con los restos de un posible muro dispuesto en sentido suroeste-noreste por sobre la estructura oval y parcialmente derrumbado (Imagen $\mathrm{N}^{\circ} 2$ ).

Desde lo estructural, fueron excavados artificialmente, 15 niveles estratigráficos, los cuales tras un primer análisis de los materiales recuperados, permitieron establecer tres conjuntos distinguibles:

El primero de esos conjuntos, se encuentra comprendido entre los niveles 3 al 17, y se caracteriza por la presencia de cierta cantidad de materiales intrusivos (plásticos, restos de madera), ya que se vieron afectados por las intervenciones modernas de cableado y parquización. A partir del nivel 8 la cantidad de hallazgos arqueológicos aumenta, los materiales intrusivos parecen desaparecer y la coherencia cronológica parece ser mayor. 
Teoría y Práctica de la Arqueología Histórica Latinoamericana | Año VIII. Vol. 9 | 2019

ISSN en línea: 2591-2801 | ISSN versión impresa: 2250-866X

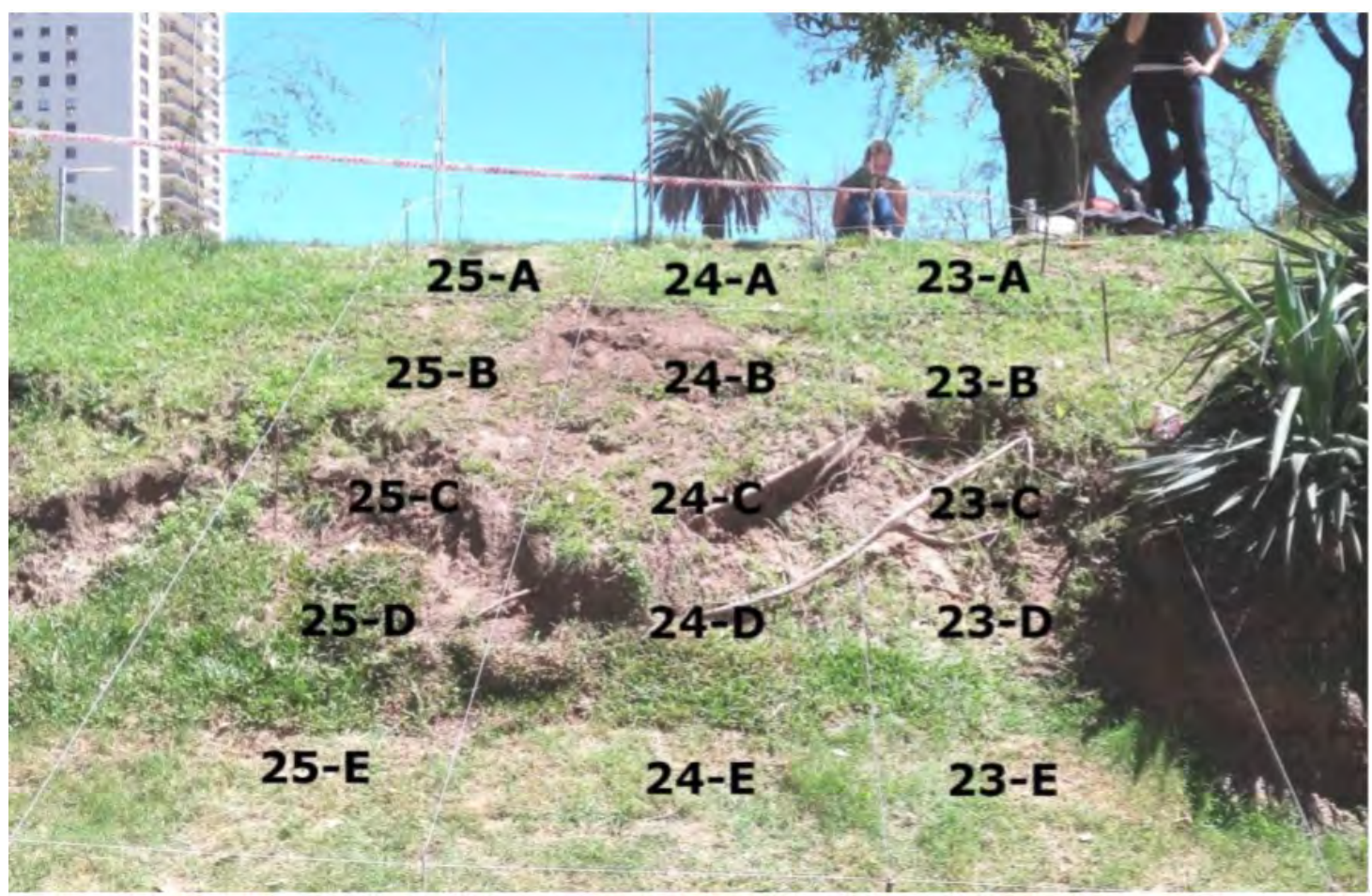

Imagen $\mathrm{N}^{\circ}$ 1. Cuadrículas planteadas en la zona de barranca sobre la calle La Pampa, frente a La Pampa 1730

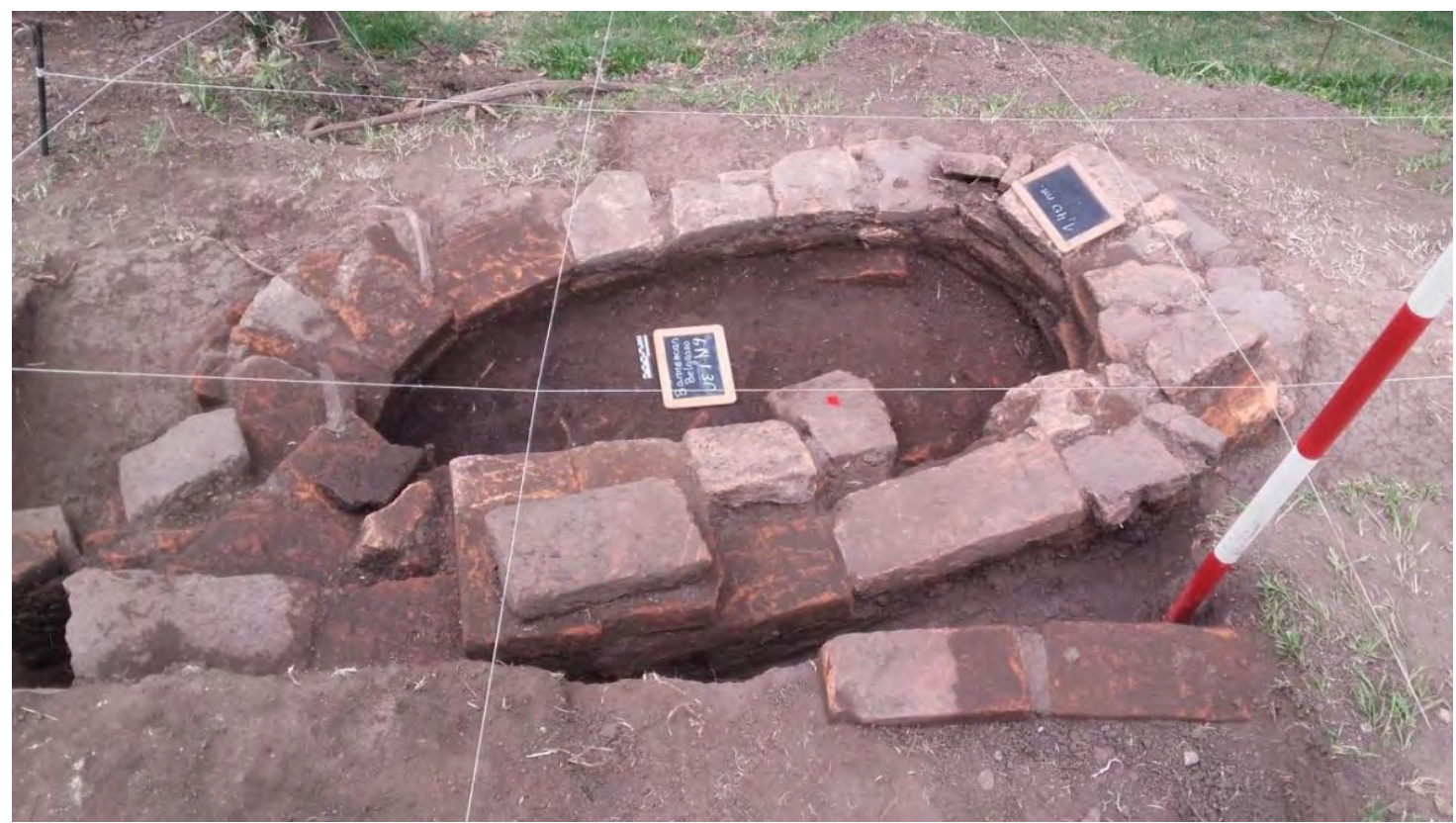

Imagen $\mathrm{N}^{\circ} 2$. Vista de la estructura oval descubierta en las Barrancas de Belgrano 
El segundo de esos conjuntos, incluye los niveles 8 al 10, y se distinguen por la presencia de objetos identificados con variados materiales culturales, con una alta fragmentación, bajo índice de remontaje y baja coherencia cronológica entre ellos. Sin embargo, este conjunto, exhibe entre el material extraído, una integridad mucho mayor que aquellos recuperados en los niveles superiores.

El último de los conjuntos, por su parte, se hallan integrados entre los niveles 11 hasta el 14 (2.05$2.85 \mathrm{mts}$ ), se aprecia un conjunto de materiales con un mayor grado de homogeneidad cronológica, presentando un alto índice de remontaje entre sí. El total del conjunto recuperado asciende a 2522, con una mayor concentración de materiales en el nivel 13, entre los 2, 45 y 2, 65 metros de profundidad. (Orsini, Bernat, Silveira, Padula 2019)

\section{Materialidad}

En los 15 niveles excavados se recuperaron 4191 restos óseos. Siendo los de mayor interés los que corresponden a los niveles 11 a 14, en los cuales no hay cortes de serrucho, ni ningún otro indicio de perturbación por ejemplo debido a raíces de árboles circundantes. El material de estos niveles es significativo por la cantidad y la variedad de especies identificadas. Es aquí donde se halló el mayor porcentaje de concentración de restos.

Este agrupamiento posee 3216 restos óseos (56 \%) y 2522 fragmentos de materiales de descarte cultural (44\%) que podemos desglosar en un 15\% de cerámicas (862) de cronologías tempranas (mayólicas, terracotas y lozas del tipo creamware, pearlware) 28\% de vidrios (1608 restos de botellas de aguardiente y vino, copas, vasos, frascos, etc.) y 57 (1\% ) restos de metales (plomada, anzuelos, monedas) (Imagen $\left.\mathrm{N}^{\circ} 3\right)$.

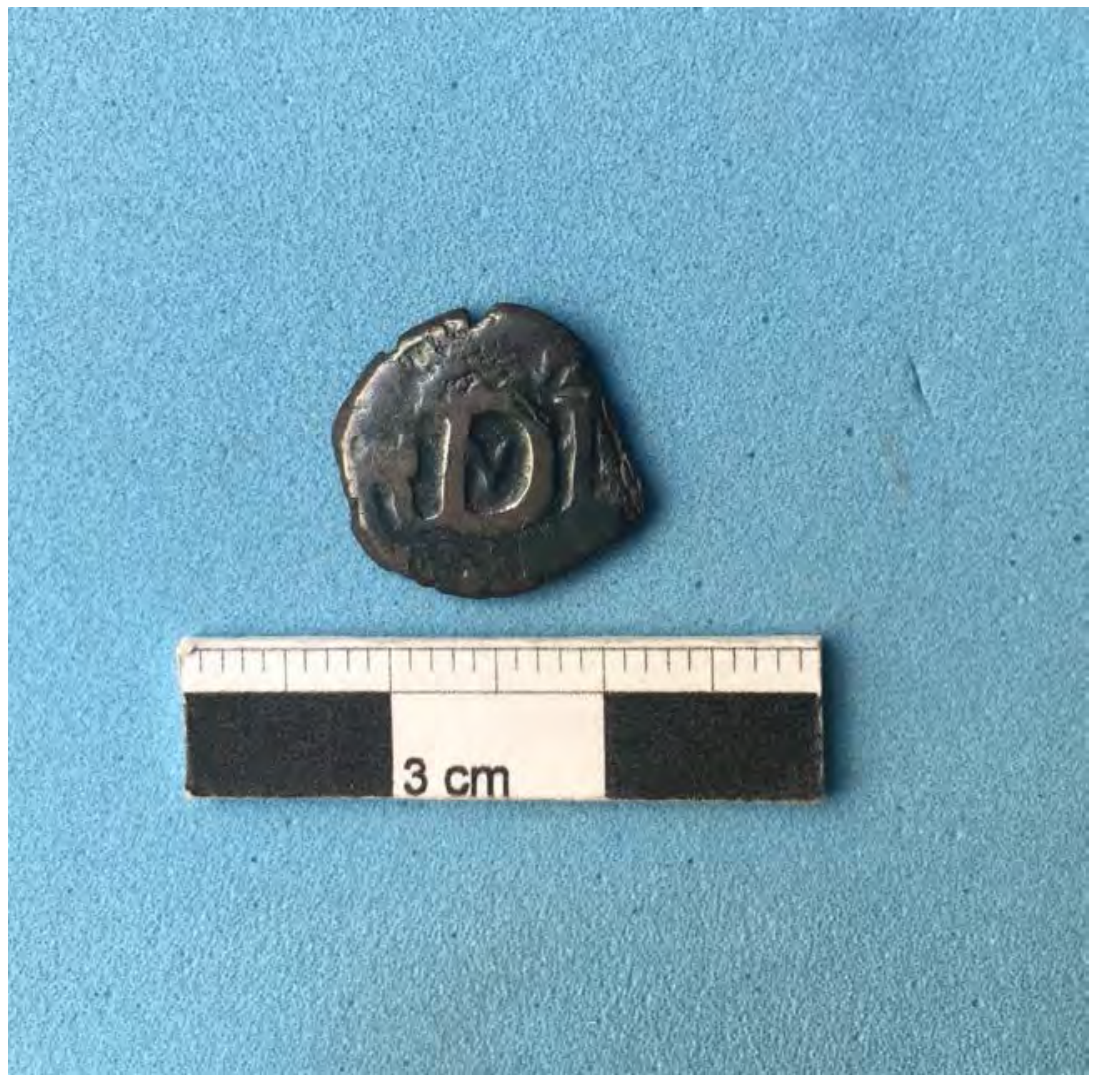

Imagen N³. Macuquina ca. 1748-60 anverso. 
Teoría y Práctica de la Arqueología Histórica Latinoamericana | Año VIII. Vol. 9 | 2019

ISSN en línea: 2591-2801 | ISSN versión impresa: 2250-866X

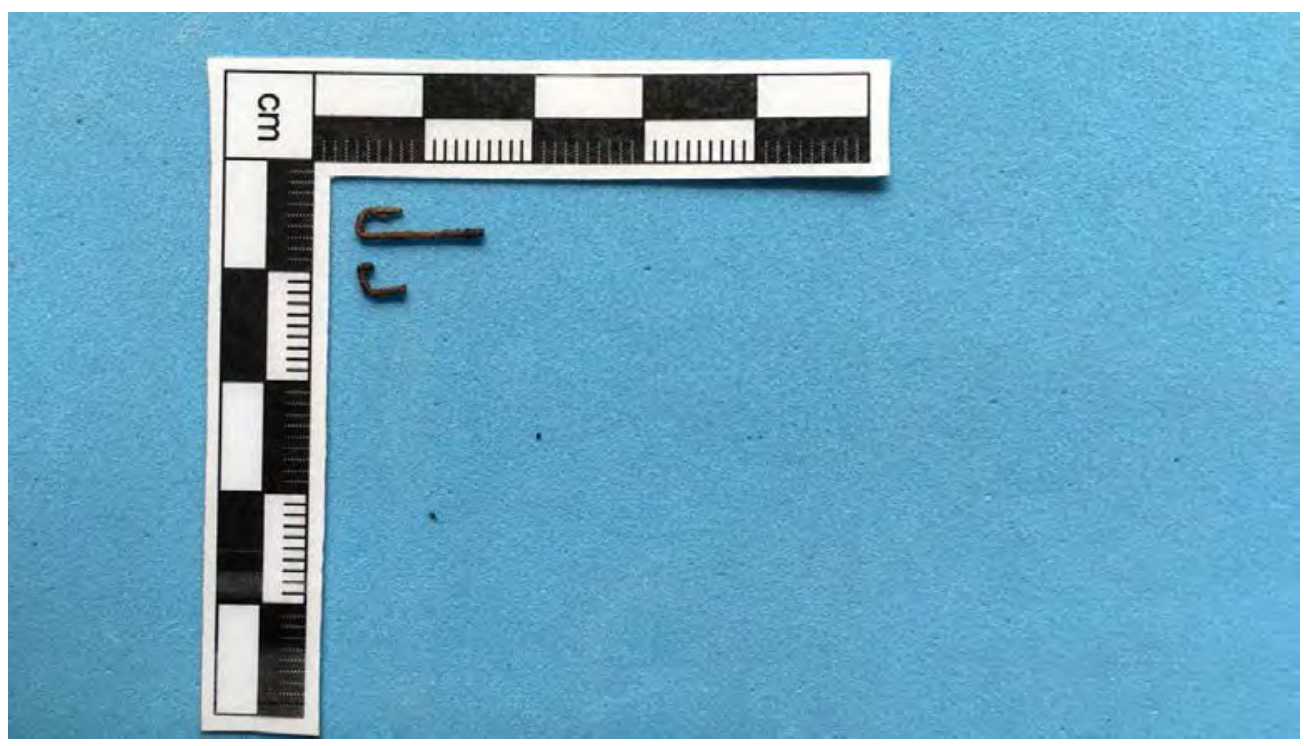

Imagen $\mathrm{N}^{\circ} 4$. Anzuelo.

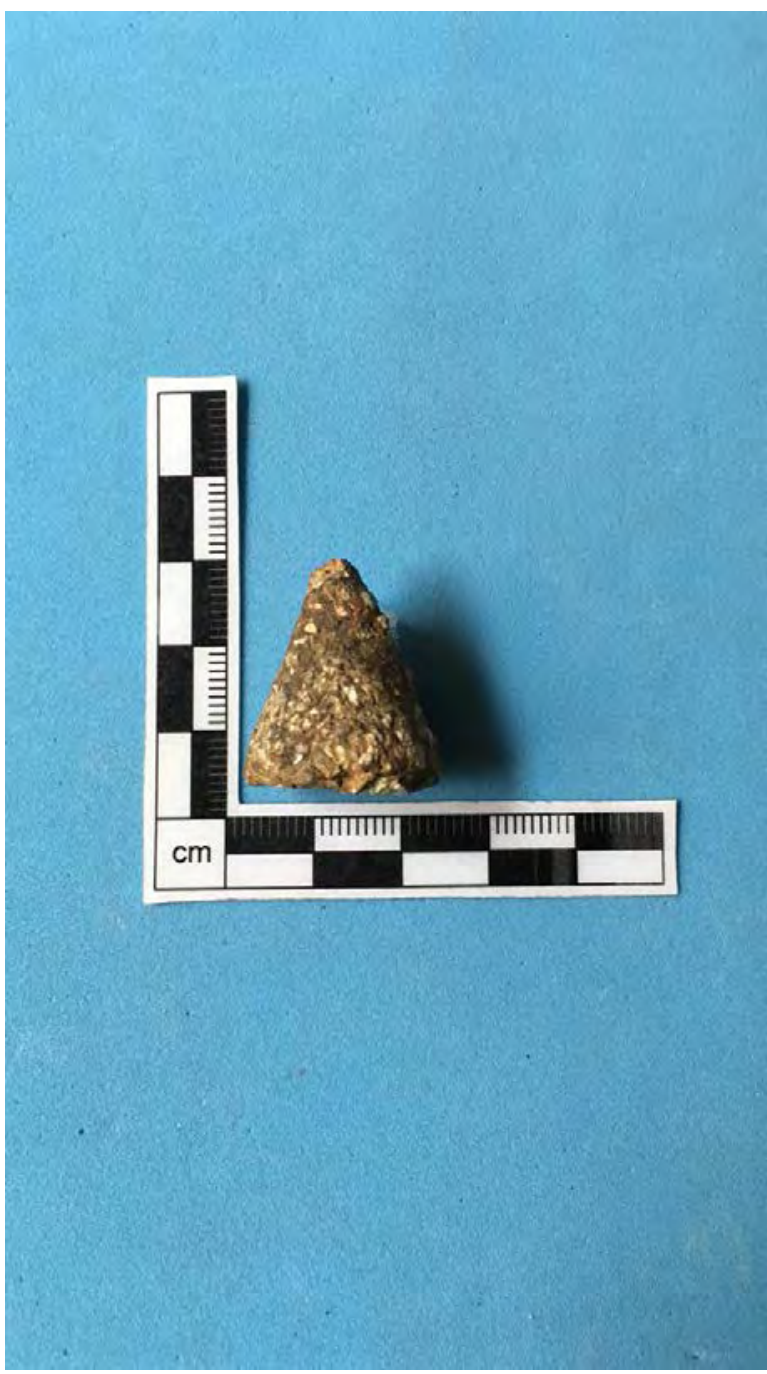

Imagen N5. Plomada para pesca 
El análisis de los restos óseos de este conjunto, en los distintos niveles taxonómicos, es el siguiente:

TABLA N 1: Especies identificadas en el sitio

\begin{tabular}{|l|l|l|l|}
\hline GÉNERO Y ESPECIE & NOMBRE COMÚN & NISP & NMI \\
\hline Bos taurus & Vacuno & 38 & 2 \\
\hline Ovis aries & Ovino & 29 & 2 \\
\hline Equus caballus & Caballo & 16 & 2 \\
\hline Sus scrofa & Cerdo & 1 & 1 \\
\hline Myocastor coypus & Coipo & 4 & 1 \\
\hline Felis & Gato doméstico & 3 & 1 \\
\hline Ratus sp. & Rata & & \\
\hline Gallus gallus & Gallina/Pollo & 72 & 7 \\
\hline Meleagris gallopavo & Pavo & 574 & 32 \\
\hline Anas versicolor & Pato & 1 & 1 \\
\hline Nothura maculosa & Perdiz chica & 1 & 1 \\
\hline Rhinchotus rusfecens & Perdiz colorada & 56 & 6 \\
\hline Rhea americana & Ñandú & 1 & 1 \\
\hline Gallinula coloropus & Gallareta común & $(1)$ & \\
\hline Columba livia & Paloma europea & 2 & 1 \\
\hline Myopsita monachus & Cotorra común & 1 & 1 \\
\hline Pterodoras granulosus & Armado común & 71 & 4 \\
\hline Odonthestes bonariensis & Pejerrey & 12 & 2 \\
\hline Prochilodus lineatus & Sábalo & 92 & 3 \\
\hline Salvator merianae & Lagarto overo & 1 & 1 \\
\hline Megaleporinus obtusidens & Boga & 1 & 1 \\
\hline Mugil sp. & Lisa & 1 & 1 \\
\hline Rhinella arenarum & Sapo común & 20 & 3 \\
\hline & & & \\
\hline Par & 2 & 2 \\
\hline
\end{tabular}

(1) Por cáscara de huevo 
TABLA $\mathrm{N}^{\circ}$ 2: Restos identificados a distintos niveles taxonómicos

\begin{tabular}{|l|l|}
\hline FAMILIA & NISP \\
\hline Anatidae (patos/gansos) & 10 \\
\hline Ardeidae (garzas) & 1 \\
\hline Pimelodidae (bagres) & 4 \\
\hline TOTAL & 15 \\
\hline ORDEN & NISP \\
\hline Rodentia (roedores en general) & 135 \\
\hline Characiformes (peces agua dulce) & 32 \\
\hline Siluriformes & 1 \\
\hline Viperidae (serpientes) & 1 \\
\hline TOTAL & 169 \\
\hline CLASE & NISP \\
\hline Mammalia (mamíferos) & 780 \\
\hline Aves & 185 \\
\hline TOTAL & 965 \\
\hline SUPERCLASE & NISP \\
\hline Ostheychties (peces) & 924 \\
\hline TOTAL & 924 \\
\hline
\end{tabular}

TABLA Nº 3: Registro malacológico

\begin{tabular}{|l|l|l|}
\hline Nombre científico & Nombre común & Cantidad \\
\hline Scolodonta semperi & Scolodonta & 1 \\
\hline Allopeas gracile & Caracol punzón & 3 \\
\hline Erodona mactroides & Erodona & 44 \\
\hline Pomacea canaliculata & Ampularia & 1 \\
\hline Diplodon sp. & Náyade & 1 \\
\hline TOTAL & & 50 \\
\hline
\end{tabular}


Se observa predominancia de erodona, aspecto natural ya que es componente mayoritario de los depósitos ocurridos en la transgresión descripta por el naturalista francés August Bravard en 1857 (Bravard 1857) a partir de un banco de conchillas al borde de la barranca, quien determinó unas 35 especies malacológicas en sus sedimentos, entre los que predominaba la especie Azara labiata (actualmente denominada Erodona mactroides).

Para el año 1889, el gran paleontólogo Florentino Ameghino, basándose en los hallazgos de Bravard le da el nombre de "Belgranense”. (Ameghino 1889) (Imagen $\mathrm{N}^{\circ} 6$ )

Los depósitos ostreros belgranenses llevan el nombre de Formación Pascua (ca. 120.000 años, es decir el Pleistoceno superior) y se supone fueron generados a partir de la trasgresión marina provocada por el derretimiento de los casquetes polares que provocó un ascenso del mar, 6 metros sobre el nivel que se encuentra actualmente (Padula y Silveira 2015).

Estos sedimentos fueron explotados por los padres de la Orden Franciscana del Convento de Santa Úrsula las Once Mil Vírgenes, que hacia 1726 fabricaron cal utilizando horno en las tierras que les concedieron en la zona de las barrancas, con el propósito de usarlo para la construcción de un nuevo templo y así reemplazar su antigua iglesia que databa de 1602. No sólo utilizaron esta cal para levantar su propio templo, sino que también se lo vendían a las monjas catalinas para su convento y a los encargados de las obras de la Catedral Metropolitana, destinándose además a otras construcciones de la ciudad. (Padula y Silveira 2015

En ese tiempo en que el actual barrio de Belgrano era llamado “los alfalfares de Rosas”, el área de las barrancas era conocida como “de la Calera” (Casella de Calderón 1986).

Bravard comenta también a cerca de la solidez de los depósitos belgranenses, afirmando que la iglesia del pueblito de Belgrano se edificó con “pedruzcos de esa substancia” (Bravard 1857, p.28)

Los restos de esta especie, detallados en nuestro trabajo no solo se observaron sueltos dentro del sedimento, sino que también se los encontró formando parte de “coquinas” un tipo de roca sedimentara (conglomerado) cuyos clastos lo componen restos de moluscos. Los demás moluscos encontrados corresponden a especies actuales de las cuales solo la ampularia y la náyade son consideradas comestibles, pero se descarta esa posibilidad debido a su bajo número de hallazgos. 
Teoría y Práctica de la Arqueología Histórica Latinoamericana | Año VIII. Vol. 9 | 2019

ISSN en línea: 2591-2801 | ISSN versión impresa: 2250-866X

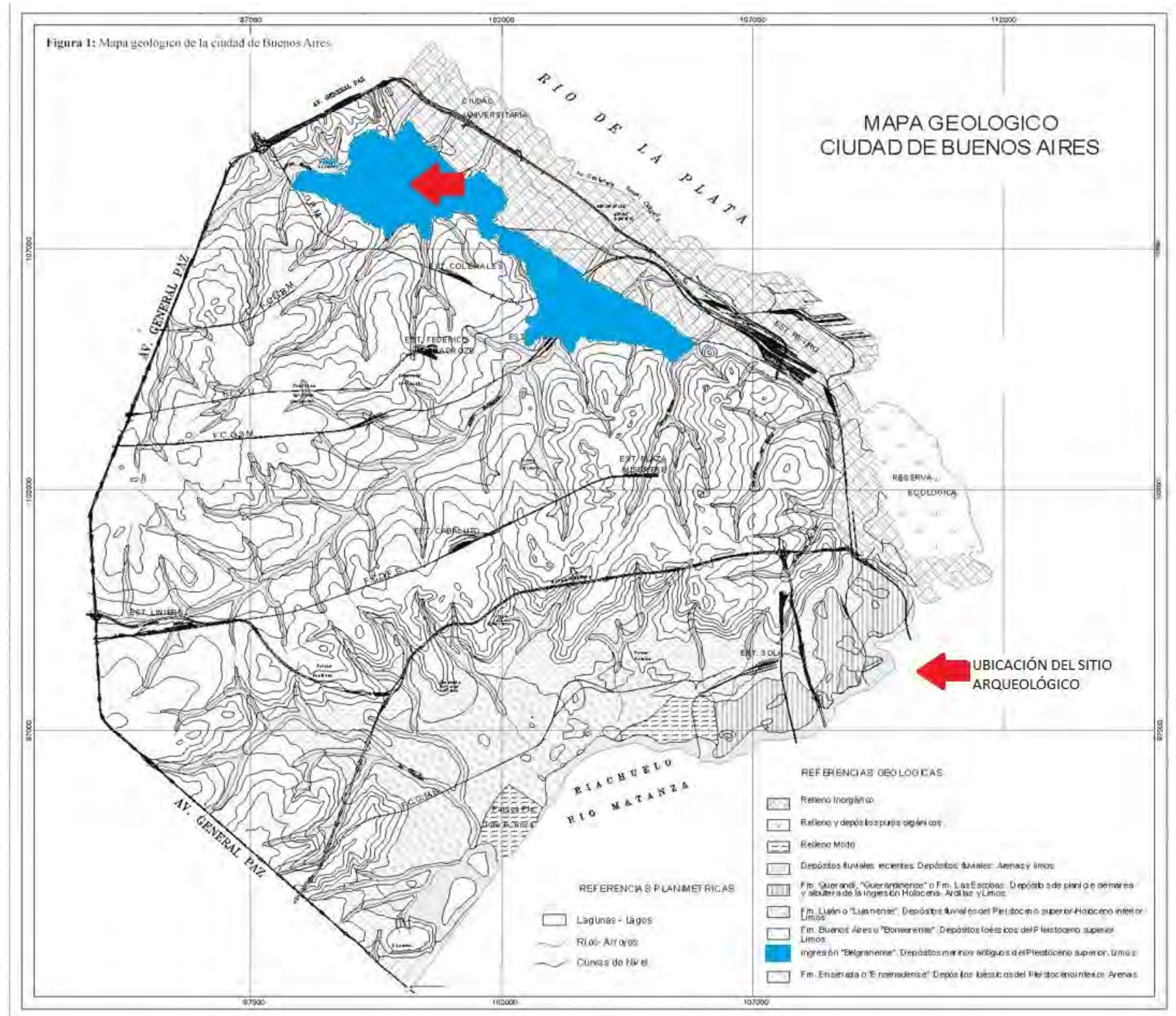

Imagen $\mathrm{N}^{\circ} 6$. Afloramiento de sedimentos "belgranenses" que existía en las barrancas, actualmente imposible ser visto debido a las construcciones y calles de la ciudad con la localización del sitio arqueológico. 


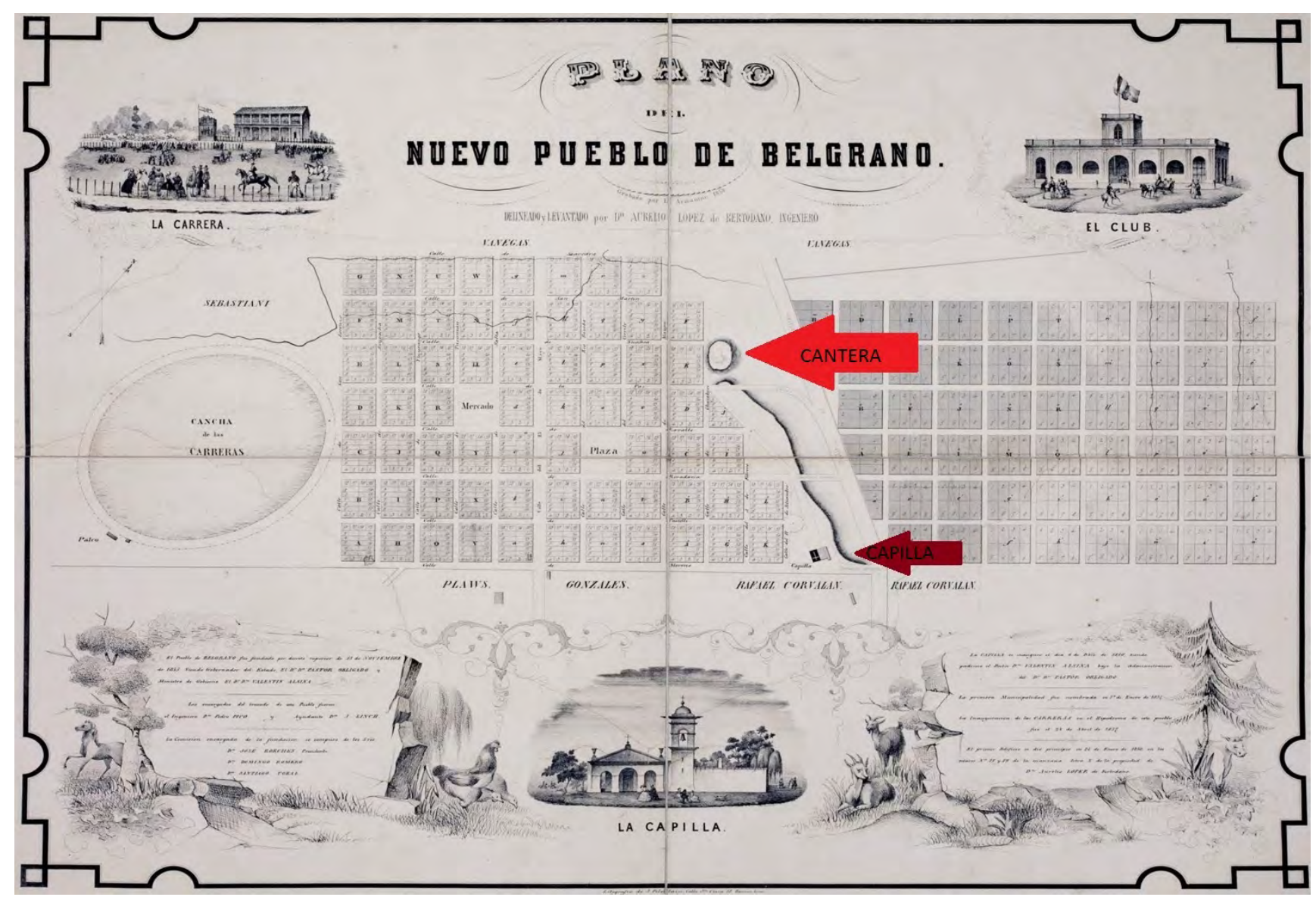

Imagen Nº7. Plano del Nuevo Pueblo de Belgrano, Aurelio López de Bertodano (año 1858) donde se observa la localización de la zona de extracción de roca para la producción de cal por parte de la Orden Franciscana y la ubicación de la capilla

No consideramos en este artículo el análisis detallado de los huesos de cada especie, familia, orden o clase, salvo en algunos casos que interesan en las conclusiones.

Se agruparon los restos en dos categorías, una, que considera animales domésticos y salvajes, la otra cuales fueron realmente consumidos y cuáles no. 
TABLA N 4: ANIMALES DOMESTICOS Y SALVAJES

\begin{tabular}{|l|l|}
\hline DOMESTICAS & SALVAJES \\
\hline VACUNO & PATOS \\
\hline CABALLO & PERDICES \\
\hline OVINO & PALOMA \\
\hline PERRO & COTORRA COMUN \\
\hline GATO & GALLARETA COMUN \\
\hline POLLOS Y GALLINAS & GARZA \\
\hline & MICROROEDORES \\
\hline & RATAS \\
\hline & COIPO \\
\hline & LAGARTO OVERO \\
\hline & SAPO \\
\hline & SERPIENTE \\
\hline & NANDU \\
\hline & ARMADO \\
\hline & SABALO \\
\hline & PEJERREY \\
\hline & LISA \\
\hline & BOGA \\
\hline & AMPULARIA \\
\hline & SCOLODONTA \\
\hline & CARACOL PUNZÓN \\
\hline & NÁYADE \\
\hline
\end{tabular}

TABLA N ${ }^{\circ}$ :

ANIMALES CONSUMIDOS Y SIN CONSUMO

\begin{tabular}{|l|l|}
\hline CONSUMO & SIN CONSUMO \\
\hline VACUNO & CABALLO \\
\hline OVINO & GATO \\
\hline POLLOS Y GALLINAS & PERRO \\
\hline PERDICES & RATAS \\
\hline PATOS & MICROROEDORES \\
\hline ÑANDU & COTORRA COMUN \\
\hline ARMADO & GALLARETA COMUN \\
\hline SABALO & GARZA \\
\hline PEJERREY & SAPO \\
\hline LISA & LAGARTO OVERO \\
\hline BOGA & SERPIENTE \\
\hline & COIPO \\
\hline & PALOMA \\
\hline & AMPULARIA \\
\hline & NÁYADE \\
\hline & SCOLODONTA \\
\hline & LAMELAXIS \\
\hline
\end{tabular}


Puede resultar raro que no consideremos al caballo como de no consumo, teniendo en cuenta que hay información de su ingesta en los siglos XVIII y XIX, en particular por indígenas bonaerenses, aunque también hay un registro de consumo en la ciudad de Buenos Aires para el siglo XIX, aunque aún no se ha publicado (Silveira et al 2019). Para el caso de la estructura de Barrancas de Belgrano los huesos de Equus caballus identificados consisten en dos mandíbulas, autopodios y un metatarso. Estos huesos se caracterizan por no tener carne o presentarla en cantidades ínfimas (Imágenes №7 y 8). Nuestra hipótesis es que las mandíbulas pudieron haber sido utilizadas como un instrumento musical de percusión, conocido como “charaina”, muy frecuente entre grupos de origen "afro" y cuya presencia en el sitio es mencionado en los documentos de la época (Casella de Calderon, 1986, p.26). La bibliografía consultada, asevera que este tipo de instrumento aún se utiliza en algunos países de América Latina, como es el caso en Perú y Ecuador (Beck, 2007).

Con respecto al metatarso, presenta un lascado de unos $8 \mathrm{~cm}$ a partir de la epífisis proximal. Es justamente un espacio para poder retirar la piel del hueso para obtener una bota de potro. Essex Vidal en 1818 había observado: “...Botas, de las que se usan generalmente en las clases bajas en el campo, hechas con la piel de las patas traseras de potro” (Vidal Essex 1999, p.105).

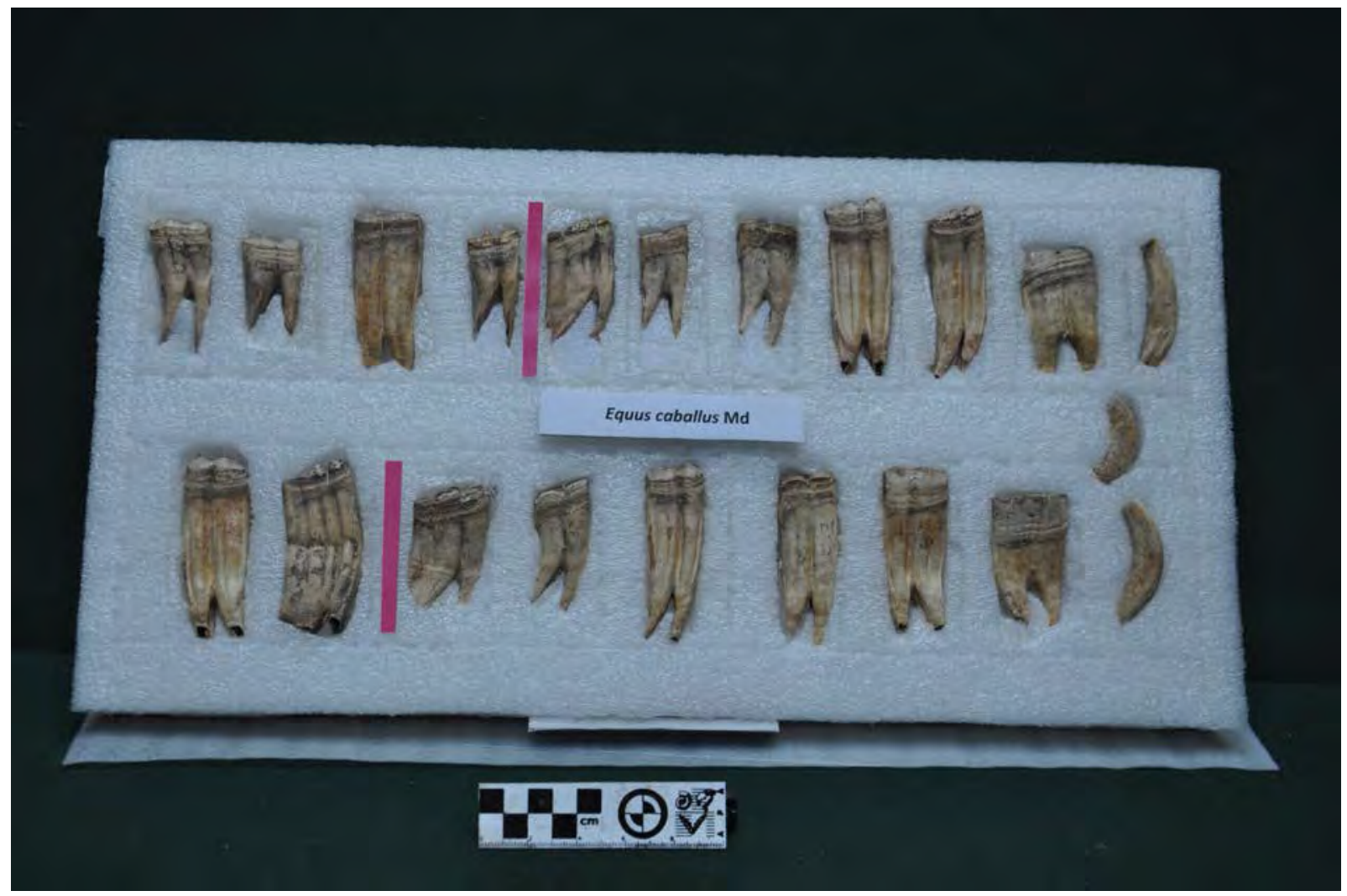

Imagen N8. Dentición de Equss caballus hallada en la excavación.

La especie más consumida fue Gallus gallus con un NISP de 574 elementos (huesos reconocidos) y un MNI (número mínimo de individuos) de 32. Esta cantidad, más la presencia de gallo, gallina pigmea y el hallazgo de un esqueleto articulado completo de la especie (ejemplar que no fue consumido pues debió provenir de un ave que tenía alguna enfermedad por la cual fue eliminado), nos hace presumir que en el lugar se tenía un gallinero. 
En la excavación hay muchos restos de cascara de huevos, incluso dentro de una botija hallamos las dos mitades de una cáscara de un huevo de este ave. Algo similar, respecto a un gallinero, fue observado en el análisis de los restos óseos del Convento de Santa Catalina situado en la ciudad de Buenos Aires (Schávelzon y Silveira 2005).

Entre las especies domésticas el consumo de vacuno fue bajo, considerado como mayoritario en Buenos Aires en ese tiempo. Solo un NISP de 68 con un MNI de 2.

También Ovis aries revista un consumo bajo con un NISP de 19 y un MNI de 2. Este taxón se analizará luego en las conclusiones.

En cuanto a especies salvajes, el pescado, con distintas especies (cinco por lo menos), fue el alimento más consumido después de pollos y gallinas. Hemos hallado evidencia de elementos de pesca: una pequeña plomada de forma cónica con un agujero en su parte media para pasar el sedal y un fragmento de un anzuelo metálico (Imágenes $\mathrm{N}^{\circ} 4$ y 5).

Continuando con las especies salvajes, las perdices fueron las más cazadas. No era complicado, ya que se podían cazar desde un caballo con bastante facilidad (Andrews 1920), más aun dentro de un área tan rural como eran las Barrancas de Belgrano para buena parte del siglo XVIII y principios del XIX.

Los patos pudieron ser consumidos, aunque su caza debió posibilitarse por medio de armas de fuego (escopetas). Los demás restos que pudieron ser de consumo como coipo, paloma y gallareta, es dudosa la utilización ya que la cantidad de hallazgos es mínima.

La presencia en el registro de garza, serpiente, microroedores, lagarto overo y ñandú (este por cáscaras de huevos), confirma lo rural del área para la época de la ocupación.

También se hallaron objetos confeccionados a partir de material óseo, 6 botones de un agujero, que pueden ser tanto de origen europeo como manufacturados localmente (Deagan 1987,135) y un peine (Imágenes $\mathrm{N}^{\circ} 9$ y 10).

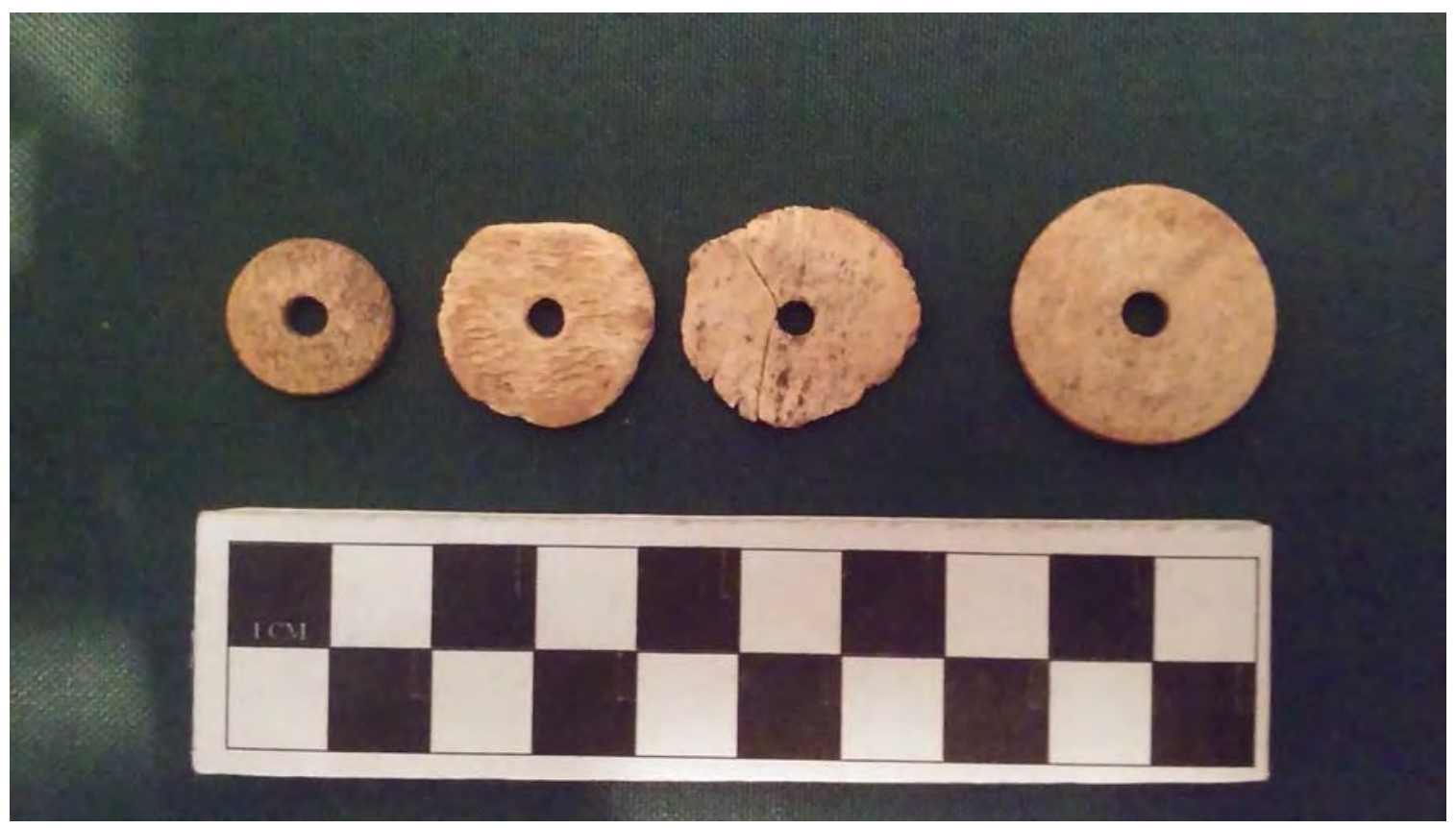

Imagen $\mathrm{N}^{\circ}$. Botones de hueso 


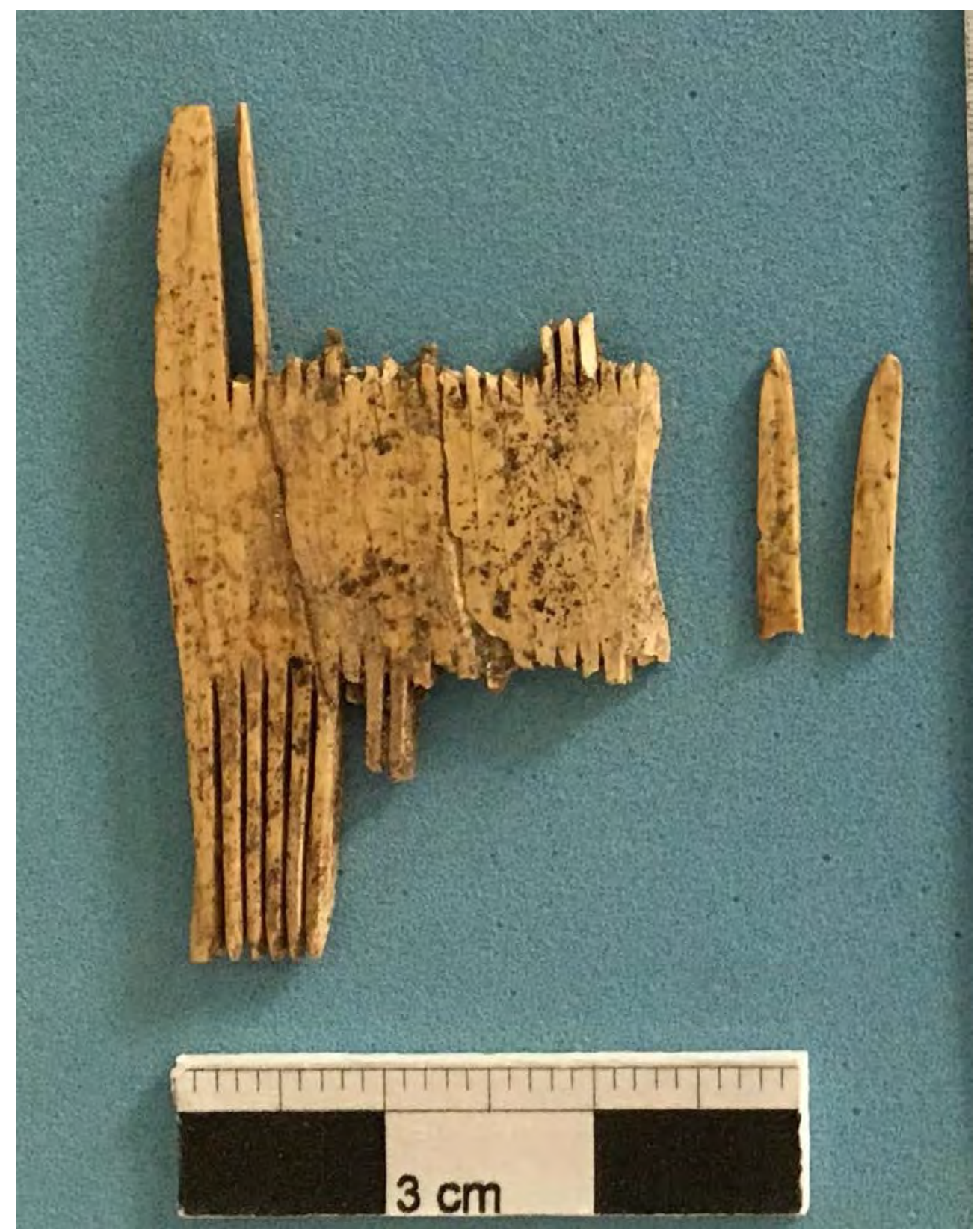

Imagen $\mathrm{N}^{\circ} 10$. Fragmento de peine de hueso.

Se destaca en este trabajo el muy buen estado de conservación del material óseo. Los procesos tafonómicos han sido mínimos. En la totalidad de los restos tenemos solamente un E1 (ataque tafonómico leve) (Silveira 1999) de solo 7 fragmentos, 14 quemados y 10 calcinados. En un caso, hay marcas de dientes de cánido y en otro, marcas de raspado. 
Teoría y Práctica de la Arqueología Histórica Latinoamericana | Año VIII. Vol. 9 | 2019

ISSN en línea: 2591-2801 | ISSN versión impresa: 2250-866X

\section{Conclusiones}

Del análisis del material podemos inducir que el depósito corresponde a un descarte primario debido a la forma en que fueron descartados los mismos, la casi inexistente alteración tafonómica, la alta concentración de 5699 fragmentos en poco más de un metro cúbico correspondiente a niveles acotados (11 al 14), el alto porcentaje de remontaje de las piezas, de 869 fragmentos 799 han podido ser remontados. Este mismo proceso se observa en los vidrios. Rearmándose un total de 42 objetos.

La hipótesis más probable es que los restos provengan de la segunda etapa de ocupación de las Barrancas, 1775-1825. Esta aproximación cronológica coincide también con el hallazgo de una moneda de plata, acuñada en 1797, y por la ausencia de lozas Whiteware, las cuales podrían extender la cronología promedio más allá de las primeras décadas del siglo XIX. También el análisis óseo nos indica un consumo bajo de Ovis aries. Si consideramos que los restos correspondieron a los franciscanos, quienes habían llevado una majada importante de esos animales en su primera estadía en las Barrancas de Belgrano. En el inventario del año 1774, cuando los franciscanos son expulsados del lugar al entrar en litigios con la familia Espinosa (supuestos propietarios de esas tierras), se declaró que la Orden poseía 1800 ovejas, las que habrían sido llevadas durante la desocupación. (Casella de Calderón, 1986).

Un año después de aquel desalojo, los franciscanos vuelven a las tierras de "la Calera" como se la solía llamar, tras recibir una donación de tierras en un lote vecino al de los Espinosa. En esta segunda etapa de ocupación de las Barrancas, 1775-1825, no se habla de majada alguna, lo cual es corroborado por el registro arqueológico. Esto nos indica que los restos hallados en la excavación pertenecerían a este segundo período de ocupación de la Orden en el lugar.

Por último la asociación con la Orden Franciscana se da por el hallazgo de objetos que podrían estar relacionados a la liturgia; como una posible vinajera de vidrio transparente muy fino, tallado en el cuello y en el pico de probable origen inglés. “.. Las vinajeras podían ser de metal o cristal, y sirven para suministrar el agua y el vino necesarios para el sacrificio. Las misma se presenta en el altar en un platillo y otros objetos como un jarrón o florero, una copa tallada con pie dorado en oro y un lebrillo, la versatilidad en los usos de este objeto lo torna una pieza muy interesante ya que puede asociarse entre sus funciones la de higiene personal, transporte de alimentos y también en un reciente trabajo se le atribuye función como pila bautismal” (comunicación personal Alejandro Cáceres, curador y coordinador del Museo Franciscano “Fray María Bottaro”) no sería extraño pensar este uso en el contexto Franciscano.

Nos encontramos entonces, con que los hallazgos de restos óseos que pueden asignarse a desechos alimenticios se asocian, en gran parte, a especies que se encontraban en estado salvaje (peces y perdices principalmente) lo cual se entiende dado la cercanía del sitio con la costa del Río de la Plata para entonces y la ubicación netamente rural. Mientras que entre las especies domésticas es remarcable la presencia de restos óseos y cáscaras de huevos de gallinas, debido seguramente al establecimiento de un gallinero en épocas en que la Orden Franciscana se asentaba en el sitio.

\section{Agradecimientos}

Deseamos expresar un sincero agradecimiento al señor Sergio Bogan por su inestimable ayuda a la hora de determinar las especies de peces halladas en el sitio. 
Teoría y Práctica de la Arqueología Histórica Latinoamericana | Año VIII. Vol. 9 | 2019

ISSN en línea: 2591-2801 | ISSN versión impresa: 2250-866X

\section{Referencias bibliográficas}

AMEGHINO, F. (1889). Contribución al conocimiento de los mamíferos fósiles de la República Argentina. Córdoba, Argentina: Actas de la Academia Nacional de Ciencias de Córdoba,

ANDREWS, J. (1920). Viaje de Buenos Aires a Potosí y Arica en los años 1825 y 1826. Buenos. Aires. Argentina: La Cultura Argentina.

BECK, J. (2007). Encyclopedia of percussion. New York. EE.U: Ruthledge.

BRAVARD, A. (1857). Observaciones geológicas sobre diferentes terrenos de transporte en la Hoya del Plata. Buenos Aires. Argentina.

CASELLA DE CALDERÓN, E. (1986) “Buenos Aires nos cuenta” №26 Buenos Aires. Argentina.

DEAGAN, K. (1987). Artefactos de las colonias Españolas de la Florida y el Caribe. Volumen 2.Washington. EE.UU: Smithsonian Press.

ESSEX VIDAL, E. (1999). Montevideo y Buenos Aires. Buenos Aires. Argentina: Emece Editores.

MILLÉ, A. (1961). Crónica de la Orden Franciscana. En la conquista del Perú, Paraguay y el Tucumán y su convento del Antiguo Buenos Aires 1212 - 1800 Buenos Aires. Argentina: Editorial Emece

PADULA, H. y M. SILVEIRA. (2015). Restos malacológicos hallados en sitios históricos de la Ciudad de Buenos Aires en Arqueomalacología. Abordajes metodológicos y casos de estudio en el Cono Sur. Buenos Aires. Argentina: Hammond, H. y Zubismendi, A. editores.

SCHÁVELZON D .y M. SILVEIRA. (2005). La vida cotidiana en el convento de Santa Catalina de Siena a través de la Arqueología. En: Revista del Instituto de Arqueología y Museo de la Facultad de Ciencias Naturales e Instituto M. Lillo. Tucumán. Argentina: Universidad Nacional de Tucumán.

SILVERIA, M. (1999). Tafonomia en la llanura interserrana bonaerense. La Plata, Argentina: Actas del XI Congreso Nacional de Arqueología. Mendoza Argentina. Politis, G. y Berón, M. Editores.

SILVEIRA, M., R. ORSINI, E. BERNAT y H. PADULA (2019)“Francisanos en la Calera de las Barrancas”. Buenos Aires, Argentina: Gobierno de la ciudad de Buenos Aires. En prensa.

SILVEIRA, M., R. ORSINI, E. BERNAT H. PADULA y L. SOSA (2019) Estados Unidos 944. Arqueología en los suburbios de la ciudad. Buenos Aires. Argentina En prensa.

Recibido: 27 de mayo de 2019

Aceptado: 1 de julio de 2019 